\title{
Searching for Smart City definition: a comprehensive proposal
}

\author{
Renata Paola Dameri \\ University of Genova, Department of Economics (DIEC) \\ Via Vivaldi, 2 - 16126 Genova, Italy \\ dameri@economia.unige.it
}

\section{ABSTRACT}

During the latest years, smart city projects have been more and more popular and widespread all over the world. The continuous increasing of city's population and the complexity of city management drive local governments towards the strong use of technologies to support a higher quality of urban spaces and a better offering of public services. The fascination of smart cities, able to link high technology, green environment and well-being for citizens, interests all the municipalities, independently on their dimensions, geographical area or culture. However, the concept of smart city is far from to be unambiguous. Several experiences all over the world show that cities define themselves as smart, but the meaning attributed to this word is different each time. Smart city concept has been growing from empirical experience, therefore a systemic theoretical study about this phenomenon still lacks. In this paper, the author aims to propose a comprehensive and verified definition of smart city, based on both a deep literature investigation about smart city studies and a large survey of smart city projects in the international panorama. The goal of this work is not only to provide a clear framework about this interesting and current topic, but also to support local governments and public administrations in effective smart city implementation, able to create public value and well being for citizens and environmental sustainability in the urban space.

\section{Indexing terms/Keywords}

Smart city, digital city, e-government, intellectual capital.

\section{Academic Discipline And Sub-Disciplines}

Information technology; e-Government; Smart devices; Information society

\section{SUBJECT CLASSIFICATION}

Smart city

\section{TYPE (METHOD/APPROACH)}

Literature review and theoretical analysis of smart and digital city concept

\section{Council for Innovative Research}

Peer Review Research Publishing System

\section{Journal: International Journal of Computers \& Technology}

\author{
Vol 11, No.5 \\ editor@cirworld.com \\ www.cirworld.com, member.cirworld.com
}




\section{INTRODUCTION}

Smart city is a recent phenomenon, but its diffusion has been rapidly increasing in the latest few years [1]. Smart cities are nowadays widespread all over the world; in all the continents, cities are moving towards smarter urban spaces, using high technologies to face the crucial problems linked with the urban life like traffic, pollution, city crowding, poverty.

However, a clear and sound definition of smart city still lacks, not only in the academic studies, but also in empirical applications of smart concepts and projects [2]. Indeed, a large literature survey shows what follows:

- the smart city concept is used to identify a large spectrum of heterogeneous solutions and city programs, involving different types of technologies and aiming to reach a very large set of different and not well-defined goals;

- $\quad$ in the meantime, several different words are used to define similar projects and solutions, even if each of them could easily be attributed to the idea of smart city. For example: wired city, intelligent city, digital city, technocity, and so on. The similarities and the differences between all these "cities" are generally not explained [3].

The main reason of this confusion is that smart city is not a top-down phenomenon, but a bottom-up one. The top-down process arises from a well-defined strategic vision of the smart city and it is developed applying the government rules and policies, to reach shared goals stated from the beginning.

On the contrary, the smart city idea arises from the application of technology to urban problems. In fig. 1 we can see the path of both the top-down and the bottom-up smart city birth, development and consolidation.

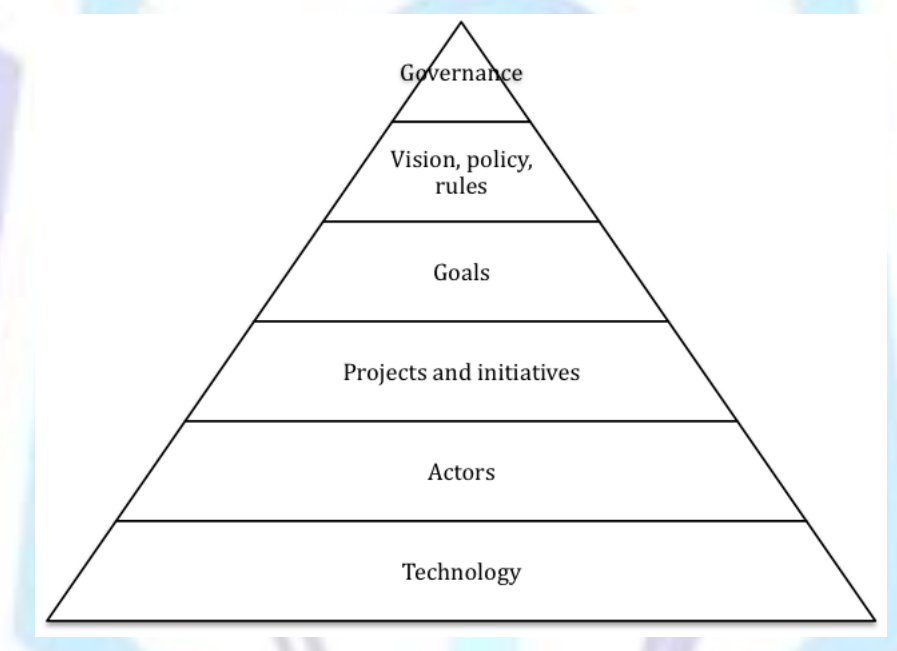

Fig 1: Bottom-up smart city development path

The main driver for smart city birth and development is technology. Especially ICT, that permits to wire and link different actors in the urban arena and to supply digital services, by both private and public institutions [4]. But also engineering and other technologies are important, especially aiming to improve logistic, mobility and environmental sustainability in the city.

Universities, research institutions and hi-tech companies are the main actors in this model: they are first movers in developing a smart city idea, using their competences to plan and implement smart solutions to support a better urban life. Their works produce a plurality of projects, initiatives and finally products and services, able to realize a small tile of the smart city patchwork $[5,6]$.

However, often a comprehensive smart city vision completely lacks. Companies and research institutions pursue their own goals, focused on specific technological areas of interest. Even if they link their own project to a broader idea of smart city, these goals are generic and not well defined, nor quantified in advance and therefore not measurable and valuable. Moreover, generic goals - such as to reduce pollution and traffic or to improve building energetic efficiency - are not referred to a strategic vision of the city, taking into account cultural, geographical and economic specificities of each urban region and its own specific aims [5].

The showed bottom-up development path often neglects two main aspects: the smart city governance and the citizens. The smart city governance is a crucial activity to grant the success of smart initiatives. Indeed, governance is the process able to address all the individual behaviors towards a common vision and goals of all the initiatives [7]. The smart city vision should be built by shared processes, involving all the stakeholders, and pursuing the definition of policies and rules: the first ones to drive the single project towards a common goal, the latter ones to state the boundaries and scope of the projects and rights and duties of all the actors [8].

The most important subjects in the smart city definition should be the citizens; however, they are often ignored. To implement a smart city initiative does not only mean to reach technological success, but to use technology to create public value. It requires to link smart projects to specific initiative, such as: to deliver high quality e-services, to achieve outcomes seen as desirable by the citizens and to increase trust in public institutions [9]. 
However, if a clear definition of smart city lacks, it is also very difficult - or impossible - to build smart cities able to really cope with the urgent challenges for a better urban space and to create real public value for people. This paper aims to propose a comprehensive and sound definition of smart city not to respond to a theoretical need, but to support public governance of smart city to define vision, goals and policies, able to drive concrete smart implementation towards desired outcomes. It especially requires to focus the definition on three aspects:

- $\quad$ to individuate the smart city crucial components;

- $\quad$ to design the perimeter and scope of a specific smart city initiative, including the important elements and excluding the redundant ones;

- to link the smart city definition to clear aims and goals, not general but specific for each city with its own history, cultural and economic profile.

\section{RESEARCH METHODOLOGY AND LITERATURE REVIEW}

As we have seen, the smart city idea was born from the application of hi-tech solutions to urban problems, but especially from the use of ICT in connecting people, political institutions and business. It requires to investigate about the smart city definition by two methods: the theoretical and the empirical one. Therefore, the author decided to collect both scientific papers about smart city and similar concepts, and reports regarding smart city projects, initiative, implementation, edited by municipalities, governmental institutions, large companies.

The literature survey shows that the topic is not so recent, because researchers started to study the ICT application to urban life from the beginning. However, especially the Internet wave and the Web 2.0 technology have been the main drivers for the development of a smart city research topic.

The literature survey includes a research regarding academic publishing, limited to double reviewed papers; it is conducted by examining published researches from ABI/Inform database and from Google Scholar. Keywords include: (smart OR digital OR intelligent OR intellectual OR techno) AND city. Afterwards, all the abstracts have been red and a subset of papers has been selected, that is, the most alike to the subject of the research.

This survey shows that two most recognized definitions are cited by the researchers: "A Smart City is a well performing city built on the 'smart' combination of endowments and activities of self-decisive, independent and aware citizens." [10]. City are smart "when investments in human and social capital and traditional (transport) and modern (ICT) communication infrastructure fuel sustainable economic growth and a high quality of life, with a wise management of natural resources, through participatory governance". [3]

These two definitions are very different each other: the first focuses on the results and on the quality of combination, the latter on the components. A deeper analysis of the collected papers, however, permits to enhance some interesting aspects, to write a definition not only theoretical, but useful to support the further concrete implementation of smart cities. These aspects are especially the role of governance, knowledge and competences in building success projects of smart city $[11,12,13,14]$. In the further paragraph, all these elements will be linked in a structured definition.

The report survey includes the most recent reports issued by both private and public institutions. On the public side, the most important actors is the EU, on the private side we can find reports issued by vendors like ABB, Alcatel, IBM, or by consultants like Accenture, Forrester, Gartner and so on. Except for a report issued by the EU in 2007 [10], regarding the rankings of medium-sized smart cities in Europe, all the reports are concentrated in the latest two years. Two different points of view emerge: the public and the private one.

The public point of view about the topic smart city outlines the need to shift the focus from the technological aspects to the economic and financial issues, especially linking goals and actions to metrics [15]. Some reports issued by EU or OECD stress the weakness of the market, both on the supply and on the demand side, and ascertain the crucial role of public policies to support smart city initiatives [16].

The private point of view outlines the need to put together the different experiences, projects, solutions, today too much scattered and lacking of a common strategy $[17,18]$. It confirms the need of the public action, but especially to state governance, policies, rules, rather than funding $[19,20]$.

The comprehensive survey supports the idea of the bottom-up development of smart city initiatives; the present situation shows a large number of small projects, lacking of control and leadership and needing of strategies, measurable goals and metrics to evaluate the smart city performance.

\section{SMART CITY ELEMENTS}

The analysis of both literature and empirical applications of smart initiatives shows that there are three crucial aspects regarding the definition of smart city:

terminology; components; boundaries and scope. 


\subsection{Terminology}

Terminology regards the words used to define the smart city. Indeed, "smart" is not the unique word used to define the same concept. However, different words sometimes define the same concept, and the same word defines different things [21]. The word "smart" is the core concept to consider, but we need both to collect other similar concepts and to understand their meaning in relation to "smart" [22]. The results of this analysis are summarized like following.

- Intelligent city. It is a city that has several competences, able to produce knowledge and to translate it into unique and distinctive abilities; it is also able to produce synergies from knowledge and competences mixed in a original way, difficult to imitate; this city is smart because it is able to create intellectual capital and to ground development and well-being on this intellectual capital [23].

- $\quad$ Digital city. It is a wired, digitalized city, using ICT both for data processing and for information sharing, but also to support communication and Web 2.0 democracy [24, 25].

- Sustainable city. It is a city that uses the technology to reduce CO2 emissions, to produce efficient energy, to improve the buildings efficiency; it aims to become a green city [26].

- Technocity. It is a city that uses the technology to improve the efficiency and effectiveness of its infrastructures and services: it focuses its smart projects on urban space quality, mobility, public transports, logistic [27].

- Well-being city. It aims to produce the best quality of life for citizens, but also to create regional attractiveness both for people and for business. The technology is only a part of the weapons used to obtain these goals, but also culture, climate, history and monuments are considered important success factors [28, 16].

Obviously, all these concepts are not in contradiction each other, as they share some aspects and are partially overlapping. But to consider all these aspects enlarges at maximum the concept of smart city, and it is misleading both to understand this concept and to drive an effective smart city implementation. Too many definitions mean a lack of focus on the really important factors.

Therefore, we should contain the meanings to produce a more specific definition of smart city, able to drive its better implementation. Therefore, the terminology should be crossed with the individuation of smart city components, to clarify what is really necessary and which are the core components of smart cities.

\subsection{Components}

The analysis of the empirical implementation of smart initiatives shows that some components are ever mentioned, even if not ever are really involved in the smart city implementation. They are the following.

- The land, that is, a geographical area upon which the projects are based.

- The technologies, both ICT and others, to realize high quality infrastructures, services and governance processes, to give the better results to people.

- The citizens, that is, people to which all the smart initiatives are addressed and who should gain benefits from the smart city.

- The government, that is, the public powers that govern this area and are appointed by the citizens for choice and decisions about the public space.

At present, the most considered component is the technology: several types of technology, not only ICT. For example, the EU SETIS smart city initiative considers technologies classified respect to four application fields: buildings efficiency, transport, electricity production, heating and cooling [30]. It involves both ICT (for example to monitor smart urban mobility) and other technologies, such as smart grids, alternative fuel vehicles, and so on.

Each technology could drive some projects and initiatives to improve the urban space quality, for example reducing pollution, reducing traffic congestion, improving the building efficiency, and so on. However, this vision doesn't consider with enough importance the other components: people, government and land.

People are an essential component of smart cities: they are not only the target of smart city initiatives, but they should be smart too. That is, they should be able to profitably use the new technologies and to create smart intellectual capital to support the smart economic and social development of their city. To include people in the smart city definition means to drive local and central government to invest in increasing knowledge economy and in reducing the digital divide, to obtain a higher digital response by citizens able to produce an economic recovery for investments in smart city projects [29].

Also Government is essential for a good smart city development. Indeed, the lack of the governance (both at local or central level) in establishing the general policies and rules for smart city implementation produces a dispersion of investments and a loss of important synergies, economies of scale and scope, to improve the return on investments in smart city [5]. Moreover, the lack of governance means also the lack of the virtuous cycle: decision - strategy - goals action - evaluation - accountability, that is, the lack of the responsibility of investment priority, effectiveness and results in the interest of citizens. To include the governance dimension into the smart city definition means to recognize the role of public government in driving the strategic goals of smart cities and in influencing the private investments towards the right directions for the city well being and quality of life [30]. 
Finally, the land is an essential component of city, before that of smart city. In this sense, land means both the material ground on which the smart city will arise, and the boundaries of the smart city. This aspect is very important, because the global horizon of the economic and social development and the local territorial innovation should go together towards the same objectives. For this reason, land could not be simply the territory on which the municipality is grounded, but something larger and very different from the material concept of space. The wired city could reach also a global dimension [31]. The crucial factor is to clearly understand which is the range of the smart city policy and the goals to be reached in this area.

\subsection{Boundaries and scope}

Strictly related to the land component of the smart city concept, the boundaries define the area on which the smart city projects and initiatives are placed. The simplest point of view considers the boundaries of the smart city corresponding with the administrative boundaries of the city. However, several others solutions are possible [32], and we can dispose them on a scale from the smaller to the largest one, considering: city, region, city networks, nation, and the global view [Figure 2].

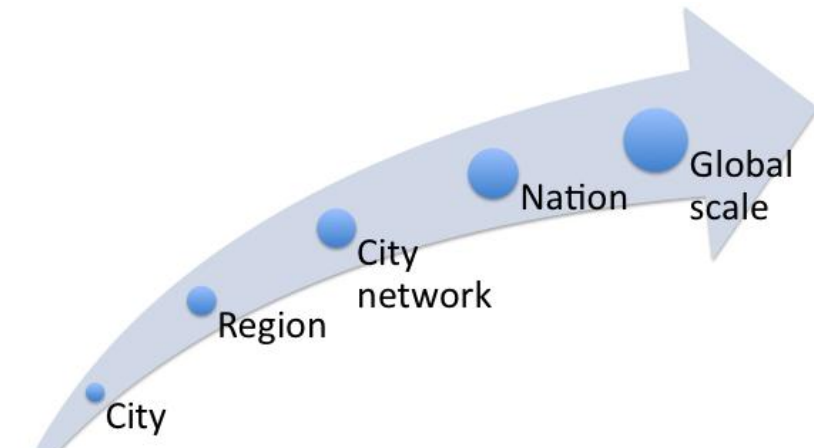

Fig 2: Smart city boundaries scale

The city, as already said, is the simplest concept of geographical area in which to develop a smart city. This choice generally depends on the role of public local government on the territory and on its capacity to drive and influence the creation of public infrastructure for smart city implementation. However, we should consider that the ICT and the Internet tend to overcome the physical and geographical boundaries, creating virtual cities and communities, far from the traditional concept of city [33]

However, the Internet creates broader opportunities, regarding a larger space for developing smart territories. To reach such goal, a global inter-urban perspective is needed, to support relationships over the local boundaries. Indeed, smart city general focuses on local-urban scale, lacking the challenge to involve in the smart initiatives larger areas and regions, to support a regional development based on learning territory with high capacity of innovation.

The Internet permits also to create relationships among smart cities and to build city networks, able to replicate best practices and to gain higher returns from investments in smart initiatives, thanks to scale, scope and learning economies. This topological solution is the best one to reach optimal results in terms of e_democracy and citizens participation to city development and innovation [35].

But cities do not grow in a vacuum: it means that they belong to a nation and the local government policies should be accorded with national policies for a harmonized smart cities dissemination and growth [36]. Current economies and social wellness increasingly depend on digital knowledge and information; smart cities are not only an opportunity for local development, but a national opportunity of economic growth. The economic crisis has further propelled the use of ICTs, which are regarded as agents of economic growth and a catalyst for structural economic and social change. Policy makers cannot loose the challenge to bridge these technologies and their applications in smart city with their political purposes to generate benefits for citizens. For these reasons, the local-urban horizons should be harmonized with national policies and supported by rules and funding for a better alignment of smart city initiatives with social and economic goals and a better cost-effectiveness ratio [36].

The larger scale is the global one, where smart cities relate each other using ICT and share best practices and smart initiatives to better and faster realize a global smart city network, to join all the smart places in the world, able to supply the best live environment to their citizens. This global view is supported by international govern institutions like OECD and EU: the EU SETIS initiative, even if restricted to energy and climate objectives, is a powerful instrument to drive local government to implement smart city initiatives, accorded with the common European goals.

Also the scope of smart city is not ever well defined. Sometimes, cities adapt to the national or EU goals, sometimes goals are too vague and fuzzy to really support effective smart implementations. Examining both the literature and the empirical smart city cases, four main set of goals can be defined. 
- Environmental sustainability. This is the most recurring goal and it is strictly linked both to the most critical urban problems (traffic, pollution, waste) and to the most important hard technologies involved in smart city implementation such as energy production, mobility, logistic and so on. This goal is also easier to measure, because it is linked to quantifiable results to be reached. However, not ever the relation between the quantitative indicators and the benefits created for the citizens is direct and demonstrable.

- Life quality and well-being. This is the broader goal, but it is often linked not only to smart initiatives strictu sensu, but more generally to all the policies of the local government, regarding for example culture, environment, sport facilities, schools, ... In this case, the smart city goals are misleading and also the measurement of the results obtained by smart projects are not correctly measured. These goals should be limited to the ones obtained by smart initiatives, supported by high technologies, both ICT and others; the difficult in this case is to detach the outcomes deriving from the smart initiatives form the others.

- Participation. It requires the active role of citizens in participating to the city governance and to exercise a democratic role in the city choices. It is strictly related to the e-government initiatives and it depends especially from the digital city, on the presence of public e-services and on the digital awareness and culture of the city population.

- Knowledge and intellectual capital. It is intangible aspect of the smart city. It reminds that a smart city in not only based on hard resources, but also on intangible ones, such as intellectual capital. This goal considers intellectual and smart capital ad the most important resource for a better economic and social development of smart city and requires to create smart people initiatives to promote and realize such type of smart city implementation.

\section{SMART CITY COMPREHENSIVE DEFINITION: CONCLUSION AND FURTHER STUDIES}

The definition of a comprehensive smart city concept should take in consideration all the elements examined above: components, boundaries, scope and the terminology.

Summarizing:

- a smart city is made by land, citizens, technology and governance;

- it could have larger or broader boundaries, from the local urban dimension of a single city, to a region, a network of city, towards the national and global dimension;

- it should have well defined and measurable goals, regarding these aspects: the environmental sustainability, the creation of smart intellectual capital, the citizens participation and the well being;

- $\quad$ it is smart because it is intelligent, digital, wired, sustainable, inclusive, democratic, ...

It is now possible to try to write a comprehensive definition of the smart city:

"a smart city is a well defined geographical area, in which high technologies such as ICT, logistic, energy production, and so on, cooperate to create benefits for citizens in terms of well being, inclusion and participation, environmental quality, intelligent development; it is governed by a well defined pool of subjects, able to state the rules and policy for the city government and development" (Figure 3).
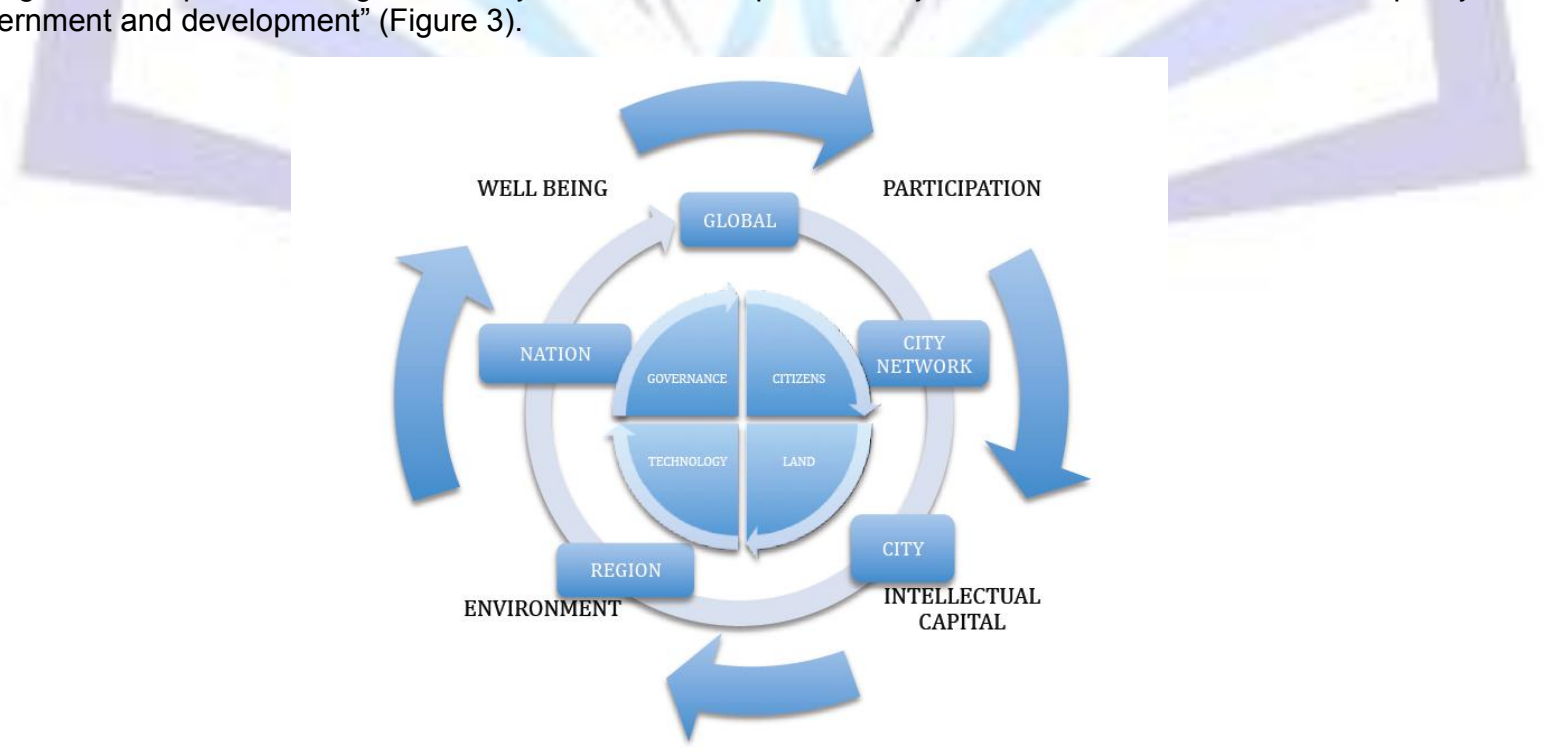

Fig 3: Smart city comprehensive schema 
Further studies will apply this definition to a set of empirical smart city, to measure the conformity between the empirical definition and the concrete realization of smart cities. Moreover, the definition, especially regarding the scope and boundaries of the smart city, will be used to support the development of a smart city evaluation tool, both to assess the effectiveness of public policies and private initiatives aiming to implement a smart city, and to drive the strategic definition of goals to be reached and benefits for he citizens to be delivered

\section{REFERENCES}

[1] Kourtit K., Nijkamp P. \& Arribas D., "Smart cities in perspective - a comparative European study by means of selforganizing maps", Innovation: The European Journal of Social Science Research, 25:2, 229-246, 2012.

[2] Tranos E. \& Gertner D., Smart networked cities?, Innovation: The European Journal of Social Science Research, 5:2, 175-190, 2012.

[3] Caragliu, A., de Bo, C., and Nijkamp, P., Smart cities in Europe. 3rd Central European Conference in Regional Science, 2009.

[4] Chen, Yu-Tso, "Sketch industry promotion framework for smart city services by leveraging Living Lab Harmonization Cube", International Journal of Electronic Business Management 10. 2, 2012.

[5] Cosgrave E. and Tryfonas T., "Exploring the Relationship Between Smart City Ploicy and Implementation", SMART 2012: The First International Conference on Smart Systems, Devices and Technologies, 2012.

[6] Dameri R.P., "Defining an evaluation framework for digital city implementation", IEEE International Conference on Information Society, London 2012.

[7] Dameri R.P., Garelli R., "A Model for IT Governance in Business Groups", The 13th European Conference on Information Technology Evaluation, 2007.

[8] Alshuwaikhat H. and Nkwenti D., "Collaborative planning and management frameworks: Approaches to effective urban governance by adoption of emerging technologies", International Journal of Management, 20.3, 2003.

[9] O'Flynn, J. 'From New Public Management to Public Value: Paradigmatic Change and Managerial Implications', The Australian Journal of Public Administration, 2007, vol 66 no 3, pp. 353-366.

[10] Giffinger R., Fertner C., Kramar H., Meijers E. and Plichler-Milhanovic N., "Smart Cities: Ranking of European medium-sized cities. Vienna, 2007.

[11] P van den Besselaar, "E-community versus E-commerce: the rise and decline of the Amsterdam digital city," Al \& Society, 2001.

[12] C. Gu, X. Duan, T. Yu, Y. Sun, “The critical technology of digital city and its achievement,", City Planning Review, 2002

[13] M. Beatty, "Contradictions and conceptions of the digital city," Environment and Planning, 28,4, 2001.

[14] A. Aurigi, Making the digital city: the early shaping of urban Internet space, Ashgate Burlington, USA 2005.

[15] European Smart City Network, Smart cities - Ranking of European medium-sized cities. Brussels 2012.

[16] OECD, Good Governance for Digital Policies: How to Get the Most Out of ICT, OECD Publishing, Paris, 2010.

[17] Accenture, Cisco and GMA, Smart Mobile Cities: Opportunities for Mobile Operators to Deliver Intelligent Cities, April 2011.

[18] Forrester Research, Smart City Leaders Need Better Governance Tools: Smart City Governance Brings New Opportunities For Tech Providers, May 2011.

[19] Alcatel-Lucent, Getting smart about smart city, 2012.

[20] IBM, "A vision of smarter cities: how cities can lead the way into a prosperous and sustainable future", 2012.

[21] L Qi, "Research on digital city framework architecture," Info-tech and Info-net, 2001. Proceedings. ICII, Beejing 2001.

[22] Chourabi H., "Understanding Smart Cities: An Integrative Framework", 45th Hawaii International Conference on System Sciences, 2012.

[23] Tan Y., Velibeyoglu, K., Martinez-Fernandez, C., Rising knowledge cities: the role of urban knowledge precincts, Journal of Knowledge Management, 12(5), 2008.

[24] T. Ishida, "Digital City Kyoto: Social Information Infrastructure for Everyday Life," Communications of the ACM, September 12, 2000.

[25] Aurigi A., Competing Urban Visions and the Shaping of the Digital City, Knowledge, Technology and Policy, Vol.18, 2005.

[26] Batagan, L., Smart Cities and Sustainability Models, Informatica Economica, 15.3, 2011. 
[27] Downey J., McGuigan J., Technocities. London: SAGE, 1999.

[28] Caragliu a:, Del Bo C., Smartness and European urban performance: assessing the local impacts of smart urban attributes, Innovation: The European Journal of Social Science Research, 25:2, 175-190, 2012.

[29] OECD, Innovation Strategy: Getting a Head Start for Tomorrow, OECD Publishing, Paris, 2009.

[30] Y. Wang, Y. Liao, "Assessing e-government systems success: a validation of the DeLone and Mc Lean model of information systems success,", Proceedings of the 11th APDSI Conference, Hong Kong 2008.

[31] K. Ergazakis, K. Metaxiotis, "Towards knowledge cities: conceptual analysis and success stories," Journal of Knowledge Management 8(5) 2004.

[32] Tranos, E. and Gillespie, A., "The spatial distribution of Internet backbone networks in Europe: a metropolitan knowledge economy perspective", European urban and regional studies, 16, 2011.

[33] Taylor, P., World city network, London: Routledge, 2004.

[34] Tranos E., Gertner D., "Smart networked cities?", Innovation: The European Journal of Social Science Research, $25: 2,2012$.

[35] Townsend, A.M., "Network cities and the global structure of the Internet", American behavioral scientist, $44,2001$.

[36] Castells, M., The rise of the network society, Oxford: Blackwell, 1996.

[37] OECD, Good Governance for Digital Policies: How to Get the Most Out of ICT, OECD Publishing, Paris 2010.

[38]

\section{Author' biography with Photo}

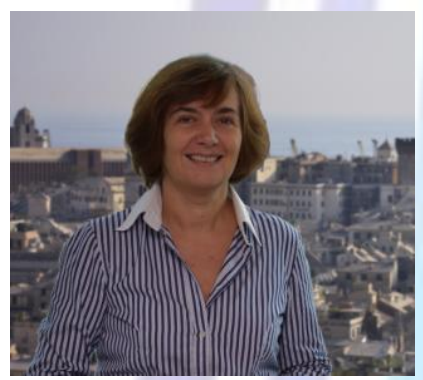

Renata Paola Dameri is researcher in Business Administration at the Department of Economics, University of Genova, Italy. She is Professor of Accounting and of Information Systems in the same University, Professor of IT Governance at Université Paris Dauphine, France, and member of the Information Systems Unit at the SDA Bocconi School of Management in Milano, Italy. Her research fields of interest are: Information Systems, Accounting Information Systems, IT Governance, IS Compliance, Smart city, Sustainable development using ICT, Intellectual capital. 